\title{
Efectos del Cadmio Sobre las Glándulas Salivales de Rata, Durante la Lactancia
}

\author{
Effects of Cadmium on the Rat Salivary Glands, During Lactation
}

"Christiane Friedrichi; ",** Ruberval Armando Lopes; "Miguel Angel Sala; *Ana Luiza de C. Felippini;

"João Paulo M. Issa; ***Ii-Sei Watanabe \& *Túlio Roberto V. P. Lopes

FRIEDRICHI, C.; LOPES, R. A.; SALA, M. A.; FELIPPINI, A. L.; ISSA, J. P. M.; WATANABE, I. \& LOPES, T. R. V. P. Efectos del cadmio sobre las glándulas salivales de rata, durante la lactancia. Int. J. Morphol., 27(4):1129-1137, 2009.

RESUMEN: El cadmio (Cd), presente en el aire, agua potable y alimentos, tiene potencial para afectar la salud humana, principalmente en las regiones altamente industrializadas. El Cd además de afectar la función placentaria, puede atravesar la barrera placentaria y perjudicar directamente el desarrollo fetal. En virtud de que el organismo es particularmente susceptible a la exposición al Cd durante el período perinatal, y que ese metal puede ser excretado en la leche, el objetivo del presente trabajo fue estudiar los efectos de la exposición continua a agua potable conteniendo bajos niveles de Cd durante la lactancia sobre las glándulas salivales de la rata. Ratas hembra recibieron agua potable conteniendo $300 \mathrm{mg} / \mathrm{l} \mathrm{de} \mathrm{CdCl} 2$ ad libitum durante toda la lactancia. Animales control recibieron un volumen similar de agua potable sin Cd. Las ratas lactantes (21 días de edad) fueron sacrificadas con una dosis letal de anestésico. Las glándulas salivales fueron separadas, fijadas en "alfac" por $24 \mathrm{~h}$, y cortadas seriadamente. Cortes de $6 \mu \mathrm{m}$ de espesor fueron teñidos con hematoxilina y eosina. Fueron estimados los parámetros nucleares, los volúmenes citoplasmático y celular, la relación núcleo/citoplasma, densidad numérica, densidad superficial, diámetros y espesor de las paredes de las estructuras glandulares. El peso medio corporal fue $34,86 \mathrm{~g}$ para la rata control y 18,56 g para la tratada. Histológicamente, los adenómeros glandulares fueron significativamente menores y los conductos glandulares fueron similares en ambos grupos. La estroma fue más abundante en los animales tratados. En conclusión, las glándulas salivales (submandibular, parótida y sublingual) mostraron retardo del crecimiento en los animales intoxicados por Cd.

PALABRAS CLAVE: Cadmio; Rata; Lactancia; Glándulas salivales; Histometría.

\section{INTRODUCCIÓN}

La transferencia de cadmio $(\mathrm{Cd})$ durante la lactancia para la cría es mayor que durante la preñez. Bhattacharyya et al. (1982) demostraron que menos del $3 \%$ del Cd materno es transferido para el feto durante la gestación, mientras que, a través de la leche es transferido para las crías $11 \%$ del $\mathrm{Cd}$ recibido por la madre durante la lactancia y $25 \%$ del Cd recibido por la madre durante la preñez y lactancia.

La Organización Mundial de la Salud (WHO, 1972) establece que la cantidad máxima permitida de $\mathrm{Cd}$ ingerido por un adulto es de $1 \mu \mathrm{g} / \mathrm{Kg} /$ día. No hay especificación de los límites para niños. Schulte-Löbbert et al. (1978) calcularon, para humanos, que durante la lactancia los niños ingieren 1,8 $\mu \mathrm{g} / \mathrm{Kg} /$ día de Cd. De modo similar, Pinkerton et al. (1976) observaron que los lactantes ingieren $2,0 \mu \mathrm{g} / \mathrm{Kg} / \mathrm{día}$ de $\mathrm{Cd}$, mientras que Sternowsky \& Wessolowski (1985) calcularon que lactantes de áreas urbanas ingieren $2,3 \mu \mathrm{g} / \mathrm{Kg} /$ día de $\mathrm{Cd}$, y los lactantes de áreas rurales $1,8 \mu \mathrm{g} / \mathrm{Kg} /$ día. Por lo tanto, a través de la leche materna, estos niños ingirieron diariamente, en los tres primeros meses de vida, el doble de Cd permitido por la Organización Mundial de la Salud para adultos. Grawé \& Oskarsson (2000) observaron que un aumento de $1 \mathrm{ng} / \mathrm{ml}$ de $\mathrm{Cd}$ en la leche provoca un aumento de $0,12 \mathrm{ng} / \mathrm{g}$ en su concentración en los riñones de las crías.

Todo el Cd administrado vía oral es retenido en los intestinos del recién nacido, pero, según la especie, puede ser absorbido entre 4 y 23\% (Bhattacharyya, 1983). Brako

\footnotetext{
* Departamento de Morfología, Estomatología y Fisiología, Facultad de Odontología de Ribeirão Preto, Universidade de São Paulo, Ribeirão Preto, São Paulo, Brasil.

** Curso de Odontología, Universidad de Franca, UNIFRAN, Franca, São Paulo, Brasil.

**** Departamento de Anatomía, Instituto de Ciencias Biomédicas, Universidade de São Paulo, São Paulo, Brasil.
} 
et al. (2003) observaron que menos de $1 \%$ del Cd ingerido por las crías a través de la leche es eliminado por las heces, concluyendo que el tracto intestinal absorbe todo el $\mathrm{Cd}$ de la leche materna, independiente de la producción de metalotioneína. Sasser \& Jarboe (1977, 1980), Sasser et al. (1978) y Kelman et al. (1978) administrando vía oral ${ }^{115} \mathrm{CdCl} 2$ observaron que el cuerpo (exceptuando el tracto gastrointestinal) de recién nacidos de rata, cerdo y cobayo absorvió 1,4\%, 2,4 \% y $6 \%$ del Cd, respectivamente. El tracto gastrointestinal retuvo de $80 \%$ a $100 \%$ del metal. En la sexta semana, 0,54\% del Cd administrado se depositó en el cuerpo y $4 \%$ en el tracto gastrointestinal. Los autores demostraron, también, que cuando se administra $\mathrm{Cd}$ al 1er día de vida, el cuerpo de la rata, cerdo y cobayo acumula, entre el $7^{\circ}$ y $10^{\circ}$ día de vida, $5 \%, 4 \%$ y $23 \%$ del metal, respectivamente. Kello \& Kostial (1977) relataron la retención de elevados valores de $\mathrm{Cd}$ en recién nacidos, cuando se administra oralmente en la leche. Kostial et al. (1981) demostraron en lactantes retención de $35 \%$ del $\mathrm{Cd}$ administrado a las madres, luego de seis días de amamantamiento, 2/3 del cual se acumuló en el tracto gastrointestinal y $1 / 3$ fue absorbido y retenido en el cuerpo. La absorción fue mayor en ratas y ratones jóvenes que en adultos (Nordberg, 1975). Lucis et al. (1972) detectaron niveles significativos de Cd en el hígado e intestinos de recién nacidos, siendo que la concentración intestinal aumentó con el tiempo. Grawé \& Oskarsson (2000) no detectaron presencia de Cd en la sangre de las crías, que estaba concentrado en la corteza adrenal y en las mucosas de estómago e intestinos.

Considerando que la adición de $\mathrm{Cd}$ en la agua del bebedero, suministrada a las ratas durante la lactancia, aumenta su concentración en la leche entre 40 y $50 \mathrm{mg} / \mathrm{ml}$ en la segunda semana de lactancia, manteniendose así durante todo ese período (Crowe \& Morgan, 1997), así como la ausencia de referencias sobre su acción en las glándulas salivales durante la lactancia, el objetivo del presente trabajo es estudiar histopatologica y cuantitativamente las posibles alteraciones de las glándulas salivales en ratas cuyas madres recibieron $\mathrm{Cd}$ en la agua del bebedero durante el período de lactancia.

\section{MATERIAL Y MÉTODO}

Fueron usadas ratas blancas Wistar (Rattus norvegicus - variedad albinus), con 1 día de vida, divididas en dos grupos:

a) Grupo tratado, constituido por cinco crías, elegidas al azar de camadas de 10 lactantes, cuyas madres recibieron, durante la lactancia, $300 \mathrm{mg}$ de cloruro de cadmio por litro de agua destilada en el bebedero. b) Grupo control, constituido por cinco crías, escogidas aleatoriamente, cuyas madres recibieron, durante la lactancia, solamente agua en el bebedero.

Después del período experimental (21 días) los animales fueron sacrificados por sobredosis de anestésico (inyección de Hypnol al 3\%). Las glándulas fueron disecadas, cortadas longitudinalmente y fijadas inmediatamente en "alfac" (alcohol 80\% - 85ml, formol -10ml y ácido acético$5 \mathrm{ml}$ ), durante $24 \mathrm{~h}$. Luego de fijado y deshidratado, el material fue incluido en parafina y cortado seriadamente con 6 $\mu \mathrm{m}$ de espesor. De un total de 500 cortes fueron separados 10 por bloque y teñidos con hematoxilina y eosina.

Con la finalidad de evaluar cuantitativamente las alteraciones celulares ocurridas en las glándulas salivales submandibular (adenómeros, conductos estriados y excretores), sublingual (adenómeros, media lunas, conductos estriados y excretores) y parótida (adenómeros, conductos excretores y estriados) fueron usadas técnicas cariométricas y estereológicas. El análisis estereológico de las glándulas sublinguales no fue realizado por la imposibilidad de delimitar claramente las estructuras glandulares de los tejidos vecinos. Fueron estimados los siguientes parámetros cariométricos: diámetros mayor (D), menor $(\mathrm{d})$ y medio $(\mathrm{M})$, relación $\mathrm{D} / \mathrm{d}$, perímetro $(\mathrm{P})$, área $(\mathrm{A})$, volumen $(\mathrm{V})$, relación V/A, coeficiente de forma, índice de contorno y excentricidad (Sala et al., 1994).

Mediante métodos estereológicos fueron estimados los siguientes parámetros para adenómeros y conductos glandulares: densidad de volumen (Chalkley, 1943), densidad de superficie (Tomkeieff, 1945), diámetro medio y espesor de la pared (Sala et al., 1980, 1981).

El análisis estadístico de los resultados fue realizado mediante la prueba no paramétrica de Wilcoxon-MannWhitney (Sprent \& Smeeton, 2001).

\section{RESULTADOS}

\section{Resultados morfológicos.}

Peso materno - Al primer día del experimento el peso medio de la rata control fue $387,9 \mathrm{~g}$ y de la rata tratada 389,9 g. Al final de la lactancia los mismos fueron, respectivamente, 454,5 g y 309,5 g. Esta diferencia fue estadísticamente significativa $(\partial<0,05)$.

Peso de las crías - El peso corporal medio de la cría al $21^{\circ}$ día de lactancia fue 34,86 g en el grupo control y 18,56 g en 
el tratado, diferencia altamente significativa $(\partial<0,01)$.

Histopatología - La glándula submandibular de la rata tratada con Cd durante la lactancia mostró adenómeros y conductos con células más achatadas con núcleos picnóticos. En algunas áreas el parénquima mostró degeneraciones.

La glándula parótida de la rata tratada presentó adenómeros menores y conductos con paredes más delgadas y estriaciones menos evidentes.

La glándula sublingual del animal tratado estaba más desorganizada y con núcleos celulares más picnóticos.

\section{Resultados cariométricos.}

Glándula submandibular - Los núcleos de los adenómeros de la glándula submandibular fueron menores en el grupo intoxicado por $\mathrm{Cd}$, presentando diferencias significativas para diámetros mayor, menor y medio, perímetro, área, volumen y relación V/A. No hubo diferencia significativa de los parámetros de forma nuclear entre ambos grupos (Tabla I).

Los núcleos de las células del conducto estriado mostraron alteraciones de tamaño similares a las de los adenómeros (Tabla I). Tampoco se encontraron diferencias significativas en la forma de los núcleos de estas células entre los dos grupos.
Los núcleos de las células del conducto excretor se mostraron menores en el grupo intoxicado con Cd (Tabla I). Además de la reducción del tamaño, los núcleos presentaron diferencias significativas en su forma.

Glándula parótida - Los núcleos de los adenómeros de la glándula parótida fueron menores en el grupo intoxicado por Cd, como puede ser observado en la Tabla II, con valores significativamente diferentes $(\partial<0,01)$ para los diámetros mayor, menor y medio, perímetro, área, volumen y relación V/A. No hubo diferencia significativa de la forma nuclear entre los grupos (Tabla II).

Los núcleos de las células del conducto estriado y del conducto excretor sufrieron una reducción significativa de tamaño (Tabla II). De modo similar a lo que ocurrió en los adenómeros, no hubo alteración estadísticamente significativa de la forma nuclear.

Glándula sublingual - Los núcleos de las células de los adenómeros de la glándula sublingual fueron menores en el grupo tratado (Tabla III). No hubo diferencia significativa en las formas de los núcleos de esas células entre los dos grupos (Tabla III).

Los núcleos de las células de la media luna serosa y de los conductos estriados de la glándula sublingual no fueron afectados por el Cd (Tabla III).

Tabla I. Valores cariométricos medios de los adenómeros y conductos estriado y excretor de la glándula submandibular de ratas control (C) y tratadas con cadmio (T) durante a lactancia. Prueba de Wilcoxon-Mann-Whitney. (*) P<0,01.

\begin{tabular}{lcccccc}
\hline \multirow{2}{*}{ Parámetros } & \multicolumn{2}{c}{ Adenómero } & \multicolumn{2}{c}{ Conducto Estriado } & \multicolumn{2}{c}{ Conducto Excretor } \\
\cline { 2 - 6 } & $\mathrm{C}$ & $\mathrm{T}$ & $\mathrm{C}$ & $\mathrm{T}$ & $\mathrm{C}$ & $\mathrm{T}$ \\
\hline Diámetro mayor $(\mu \mathrm{m})$ & 6,86 & $5,55^{*}$ & 7,01 & $5,45^{*}$ & 8,07 & $5,85^{*}$ \\
Diámetro menor $(\mu \mathrm{m})$ & 5,67 & $4,52^{*}$ & 5,69 & $4,45^{*}$ & 6,21 & $4,89^{*}$ \\
Diámetro medio $(\mu \mathrm{m})$ & 6,22 & $5,00^{*}$ & 6,30 & $4,91^{*}$ & 7,06 & $5,33^{*}$ \\
Rela ción D/d & 1,22 & 1,25 & 1,24 & 1,25 & 1,31 & $1,21^{*}$ \\
Perímetro $(\mu \mathrm{m})$ & 19,75 & $15,90^{*}$ & 20,03 & $16,02^{*}$ & 22,55 & $16,92^{*}$ \\
Área $\left(\mu \mathrm{m}^{2}\right)$ & 30,68 & $20,46^{*}$ & 31,32 & $19,19^{*}$ & 39,62 & $23,21^{*}$ \\
Volumen $\left(\mu \mathrm{m}^{3}\right)$ & 129,34 & $67,77^{*}$ & 133,83 & $64,52^{*}$ & 191,11 & $82,33^{*}$ \\
Rela ción V/A & 4,15 & $3,33^{*}$ & 4,20 & $3,27^{*}$ & 4,71 & $3,56^{*}$ \\
Excentricidad & 0,50 & 0,49 & 0,50 & 0,48 & 0,57 & $0,44^{*}$ \\
Coeficiente de forma & 0,98 & 0,98 & 0,98 & 0,98 & 0,97 & 0,98 \\
Índice de contorno & 3,58 & 3,59 & 3,59 & 3,59 & 3,60 & 3,59 \\
\hline
\end{tabular}


FRIEDRICHI, C.; LOPES, R. A.; SALA, M. A.; FELIPPINI, A. L.; ISSA, J. P. M.; WATANABE, I. \& LOPES, T. R. V. P. Efectos del cadmio sobre las glándulas salivales de rata, durante la lactancia. Int. J. Morphol., 27(4):1129-1137, 2009.

Tabla II. Valores cariométricos medios de los adenómeros y conductos estriado y excretor de la glándula parótida de ratas control (C) y tratadas con cadmio (T) durante a lactancia. Prueba de Wilcoxon-Mann-Whitney. (*) $\mathrm{P}<0,01$.

\begin{tabular}{lcccccc}
\hline & \multicolumn{2}{c}{ Adenómero } & \multicolumn{2}{c}{ Conducto Estriado } & \multicolumn{2}{c}{ Conducto Excretor } \\
\cline { 2 - 6 } Parámetros & $\mathrm{C}$ & $\mathrm{T}$ & $\mathrm{C}$ & $\mathrm{T}$ & $\mathrm{C}$ & $\mathrm{T}$ \\
\hline Diámetro mayor $(\mu \mathrm{m})$ & 6,49 & $5,27^{*}$ & 6,72 & $5,15^{*}$ & 7,18 & $5,62^{*}$ \\
Diámetro menor $(\mu \mathrm{m})$ & 5,40 & $4,36^{*}$ & 5,47 & $4,12^{*}$ & 5,90 & $4,53^{*}$ \\
Diámetro medio $(\mu \mathrm{m})$ & 5,91 & $4,77^{*}$ & 6,05 & $4,59^{*}$ & 6,49 & $5,02^{*}$ \\
Relación D/d & 1,21 & 1,23 & 1,24 & 1,27 & 1,23 & 1,26 \\
Perímetro $(\mu \mathrm{m})$ & 18,73 & $15,18^{*}$ & 19,21 & $14,56^{*}$ & 20,63 & $16,02^{*}$ \\
Área $\left(\mu \mathrm{m}^{2}\right)$ & 27,64 & $18,09^{*}$ & 28,95 & $16,70^{*}$ & 33,83 & $20,02^{*}$ \\
Volumen $\left(\mu \mathrm{m}^{3}\right)$ & 110,47 & $58,75^{*}$ & 118,67 & $52,07^{*}$ & 152,72 & $68,94^{*}$ \\
Relación V/A & 3,94 & $3,19 *$ & 4,03 & $3,06^{*}$ & 4,33 & $3,35^{*}$ \\
Excentricidad & 0,48 & 0,45 & 0,49 & 0,51 & 0,49 & 0,48 \\
Coeficiente de forma & 0,98 & 0,98 & 0,98 & 0,97 & 0,98 & 0,97 \\
Índice de contorno & 3,58 & 3,59 & 3,58 & 3,60 & 3,59 & 3,60 \\
\hline
\end{tabular}

Tabla III. Valores cariométricos medios de los adenómeros, media lunas serosas y conductos estriado y excretor de la glándula sublingual de ratas control (C) y tratadas con cadmio (T) durante a lactancia. Prueba de Wilcoxon-MannWhitney. (*) $\mathrm{P}<0,05,(* *) \mathrm{P}<0,01$.

\begin{tabular}{lccccccccc}
\hline & \multicolumn{2}{c}{ Adenómero } & \multicolumn{2}{c}{ Media Luna Serosa } & \multicolumn{2}{c}{ Conducto Estriado } & \multicolumn{3}{c}{ Conducto Excretor } \\
Parámetros & $\mathrm{C}$ & $\mathrm{T}$ & $\mathrm{C}$ & $\mathrm{T}$ & $\mathrm{C}$ & $\mathrm{T}$ & $\mathrm{C}$ & $\mathrm{T}$ \\
\hline Diámetro mayor $(\mu \mathrm{m})$ & 7,99 & $7,30^{* *}$ & 6,52 & 6,54 & 6,48 & 6,18 & 6,98 & 6,53 \\
Diámetro menor $(\mu \mathrm{m})$ & 3,30 & 3,22 & 5,27 & 5,14 & 5,14 & $4,71^{*}$ & 5,17 & $4,36^{* *}$ \\
Diámetro medio $(\mu \mathrm{m})$ & 5,11 & $4,82^{*}$ & 5,85 & 5,78 & 5,76 & 5,37 & 5,99 & $5,30^{* *}$ \\
Relación D/d & 2,48 & $2,33^{*}$ & 1,25 & 1,29 & 1,28 & 1,35 & 1,37 & 1,54 \\
Perímetro $(\mu \mathrm{m})$ & 14,06 & $13,31^{*}$ & 18,59 & 18,44 & 18,34 & 17,23 & 19,24 & $17,34^{* *}$ \\
Área $\left(\mu \mathrm{m}^{2}\right)$ & 20,87 & $18,56^{* *}$ & 27,12 & 26,49 & 26,34 & 22,92 & 28,54 & $22,46^{* *}$ \\
Volumen $\left(\mu \mathrm{m}^{3}\right)$ & 114,57 & $92,64^{* *}$ & 107,69 & 103,81 & 103,43 & 83,88 & 116,99 & $82,00^{* *}$ \\
Relación V/A & 5,33 & $4,86^{* *}$ & 3,90 & 3,86 & 3,84 & 3,58 & 3,99 & $3,53^{* *}$ \\
Excentricidad & 0,90 & 0,89 & 0,53 & 0,55 & 0,54 & 0,58 & 0,60 & 0,67 \\
Coeficiente de forma & 0,97 & 0,96 & 0,98 & 0,97 & 0,97 & 0,96 & 0,96 & 0,93 \\
Índice de contorno & 3,10 & 3,11 & 3,58 & 3,60 & 3,60 & 3,62 & 3,63 & 3,69 \\
\hline
\end{tabular}

Los núcleos de las células del ducto excretor en los animales tratados, entre tanto, fueron estadísticamente menores (Tabla III), sin alteración de su forma (Tabla III).

\section{Resultados estereológicos}

Glándula submandibular - Los adenómeros de la glándula submandibular presentaron diámetro medio y espesor de la pared disminuidos en el grupo intoxicado con $\mathrm{Cd}$
(Tabla IV). Mientras tanto, la densidad volumétrica y la densidad de superficie no mostraron diferencias estadísticamente significativas entre los dos grupos (Tabla IV).

Los conductos de la glándula submandibular no mostraron diferencias significativas entre los grupos control e intoxicado por Cd (Tabla IV). La estroma conjuntiva mostró mayor densidad volumétrica en el grupo tratado con Cd (Tabla VI). 
Glándula parótida - Los adenómeros de la parótida mostraron densidad volumétrica, diámetro medio y espesor de la pared significativamente menores en los animales tratados (Tabla V). El análisis estadístico mostró ausencia de diferencias significativas en los parámetros estereológicos de los conductos de la glándula parótida entre ambos grupos.

Así como la glándula submandibular, la parótida mostró mayor densidad volumétrica de la estroma en el grupo tratado que en el control (Tabla VI).

Tabla IV. Valores estereológicos medios de los adenómeros y conductos de la glándula submandibular de ratas control (C) y tratadas con cadmio (T) durante a lactancia. Prueba de Wilcoxon-MannWhitney. ${ }^{*} \mathrm{p}<0,01$.

\begin{tabular}{lcccc}
\hline \multirow{2}{*}{ Parámetros } & \multicolumn{2}{c}{ Adenómeros } & \multicolumn{2}{c}{ Conductos } \\
& C & T & C & T \\
\hline Densidad volumétrica (\%) & 53,80 & 48,80 & 18,40 & 11,20 \\
Densidad de superficie $\left(\mathrm{mm}^{2} / \mathrm{mm}^{3}\right)$ & 1063,24 & 1114,26 & 240,82 & 189,80 \\
Diámetro medio $(\mu \mathrm{m})$ & 26,16 & $17,50^{*}$ & 30,22 & 23,22 \\
Espesor de la pared $(\mu \mathrm{m})$ & 10,08 & $8,75^{*}$ & 15,11 & 11,60 \\
\hline
\end{tabular}

Tabla V. Valores estereológicos medios de los adenómeros y conductos de la glándula parótida de ratas control (C) y tratadas con cadmio (T) durante a lactancia. Prueba de Wilcoxon-Mann-Whitney. $* \mathrm{p}<0,05, * * \mathrm{p}<0,01$.

\begin{tabular}{lcccc}
\hline \multirow{2}{*}{ Parámetros } & \multicolumn{2}{c}{ Adenómeros } & \multicolumn{2}{c}{ Conductos } \\
& C & T & C & T \\
\hline Densidad volumétrica (\%) & 55,20 & $45,00^{*}$ & 11,80 & 11,40 \\
Densidad de superficie $\left(\mathrm{mm}^{2} / \mathrm{mm}^{3}\right)$ & 1006,10 & 951,88 & 179,60 & 175,58 \\
Diámetro medio $(\mu \mathrm{m})$ & 22,12 & $19,02 * *$ & 25,30 & 24,74 \\
Espesor de la pared $(\mu \mathrm{m})$ & 10,66 & $9,50^{* *}$ & 12,66 & 12,37 \\
\hline
\end{tabular}

Tabla VI. Valores medios de la densidad volumétrica (\%) de parénquima y estroma de las glándulas submandibular y parótida de ratas control (C) y tratadas con cadmio (T) durante a lactancia. Prueba de Wilcoxon-Mann-Whitney. * $\mathrm{p}<0,05$.

\begin{tabular}{cccccccc}
\hline \multicolumn{3}{c}{ Glándula submandibular } & \multicolumn{3}{c}{ Glándula parótida } \\
\multicolumn{2}{c}{ Parénquima } & \multicolumn{2}{c}{ Estroma } & \multicolumn{2}{c}{ Parénquima } & \multicolumn{2}{c}{ Estroma } \\
\hline C & T & C & T & C & T & C & T \\
72,20 & $60,00^{*}$ & 27,80 & $40,00^{*}$ & 67,00 & $56,40^{*}$ & 33,00 & $43,60^{*}$ \\
\hline
\end{tabular}

\section{DISCUSIÓN}

El recién nacido está expuesto a los metales pesados, debido a la alta absorción intestinal durante el período neonatal, a la falta de mecanismos eficientes de excreción y a la vulnerabilidad del cerebro en rápido crecimiento y con una barrera hematoencefálica inmadura (Kostial et al., 1978; Webster \& Valois, 1981; Antonio et al., 2002, 2003).

El peso de las crías aquí usadas fue menor en el animal intoxicado con Cd que en el control. Webster (1978) observó reducción significativa del peso fetal en ratones expuestos al Cd (10, 20 o 40 ppm). Whelton et al. (1988) demostraron que las crías de lauchas que recibieron $50 \mathrm{ppm}$ de Cd pesaron hasta $25 \%$ menos, siendo que esta reducción de peso no fue provocada por disminución de ingestión materna de alimentos. En este trabajo hubo diferencia, al final del experimento, entre los pesos maternos, como fuera observado en ratas adultas intoxicadas por Cd por Braga et al., (2001). El Cd interfiere en la absorción de alimentos, inclu- 
yendo el calcio (Fassett, 1975; Nogawa, 1981; Antonio et al., 2002). El Cd compite con el Ca por los sitios de transporte del metal (Shoham et al., 1973; Christoffersen et al., 1988), explicando por qué hay mas Cd en al mucosa intestinal del animal tratado. Esto contribuye para la malnutrición de la rata y consecuente pérdida de peso corporal. El Cd interfiere, también, en la absorción intestinal de hierro, al competir directamente con el metal (Schafer \& Elsenhans, 1985; Kzolowska et al., 1993; Elsenhans et al., 1994; Schümann et al., 1996). La administración de Cd induce anemia por deficiencia de hierro, que se inicia en la lactancia, y retarda el crecimiento de las crías (Crowe \& Morgan, 1997).

Todos los medios de administración muestran que el hígado y los riñones son los que más acumulan $\mathrm{Cd}$, pero también se distribuye en otros órganos, como las glándulas salivales (Loeser \& Lorke, 1977). En el presente trabajo, la administración de Cd durante la lactancia causó alteraciones en las glándulas salivales mayores de la rata. La glándula submandibular de las crías mostró células menores en adenómeros y conductos, núcleos picnóticos y áreas de degeneración en el parénquima. Ludovice et al. (1999) relataron que crías de ratas tratadas con $\mathrm{Cd}$ durante la lactancia poseían glándulas submandibulares con adenómeros desorganizados y células menores. Los conductos estriados tenían células más bajas con núcleos menores. Los resultados histopatológicos del presente trabajo fueron confirmados por la histometría. Así, las glándulas submandibulares del grupo tratado mostraron núcleos menores en adenómeros y conductos. Los adenómeros eran menores y su pared más delgada. La densidad volumétrica del parénquima glandular era menor, con mayor proporción de estroma. Estas alteraciones confirman la literatura, señalando alteraciones de la glándula submandibular causadas por el Cd (Chiarenza et al., 1989; Pinto et al., 1998; Paula Lopes et al., 1999; Braga et al., 2001).

La parótida de las crías tratadas con Cd tenía adenómeros menores y conductos más bajos, con estriaciones menos evidentes. Los núcleos de los adenómeros y conductos eran menores, sin alteración de forma. Los adenómeros poseían diámetro y espesor de la pared disminuidos, mientras que no hubieron diferencias significativas en los conductos. El volumen relativo del estroma era mayor que el del parénquima. Estos hallazgos coinciden con los de Chiarenza et al. (1989) que relataron en la parótida, adenómeros menores y conductos con retención de secreción, áreas hemorrágicas, edema e infiltrado inflamatorio.

En el grupo intoxicado, la glándula sublingual estaba desorganizada y con núcleos celulares picnóticos. Los adenómeros y conductos excretores mostraron reducción de tamaño nuclear, sin alteración de forma. Afonso et al. (1999) observaron señales de degeneración en las glándulas sublinguales, con adenómeros menores, de células menores con núcleos achatados y numerosas vacuolas.

La secreción salival es importante para manutención de la homeostasis bucal. La estructura y función de las glándulas salivales son reguladas por neuronas simpáticas y parasimpáticas. La administración crónica de $\mathrm{Cd}$ reduce la sensibilización de las glándulas a la acción de la metacolina y norepinefrina exógenas, disminuyendo la respuesta secretora y el flujo salival (Chiarenza et al., 1989). Las células mioepiteliales son responsables por la excreción de la saliva. Estudios estructurales demuestran que la fosfatasa alcalina está confinada a las células mioepiteliales y capilares sanguíneos. Chaudhry et al. (1983) relataron que la fosfatasa alcalina de las glándulas salivales era una vez y media más sensible que la enzima del hígado y veinte veces más sensible que la enzima intestinal a la inhibición por el $\mathrm{Cd}$. Además, la actividad funcional de la fosfatasa alcalina está relacionada a la presencia de zinc (Zn) (Plocke et al., 1962), que es cofactor enzimático de la carboxipeptidasa y de la anhidrasa carbónica. El Cd, al competir con el Zn inactiva la producción de fosfatasa alcalina y, consecuentemente, reduce el flujo salival (Chaudhry et al., 1983). Abdollahi et al. (2000) observaron que el efecto inhibitorio del Cd sobre el flujo salival se debe a las alteraciones presentes en las glándulas. El tamaño, estructura, función y secreción de las glándulas salivales son mediados por el sistema autónomo, siendo el Ca el mediador intracelular más común que disciplina el proceso de secreción salival.

El mecanismo específico por el cual el Cd provoca efectos citotóxicos aún no es bien conocido. Los efectos adversos ocurren en numerosos e importantes procesos celulares, desde interrupción del metabolismo del plomo hasta la muerte celular (Morselt, 1991). El Cd, como otros metales pesados, tiene gran afinidad por los grupos sulfhidrilo de las membranas (Lijnen et al., 1991), pudiendo ser responsable por el aumento de su "permeabilidad", causando su desorganización (Visser et al., 1993). Mientras tanto, los efectos precoces del Cd no resultan del metabolismo sulfhidrilo (Prozialeck \& Lamar, 1995). El Cd inhibe la adenosintrifosfatasa de sodio y potasio (ATPasa-Na+/K+) (Lijnen et al., 1991) así como la adenosintrifosfatasa de calcio (ATPasa-Ca2+), aumentando la concentración intracelular de Ca (Visser et al., 1993; Vorbrodt et al., 1994). En cultivos de células endoteliales el Cd inhibe la ATPasa$\mathrm{Ca} 2+$ en los espacios intercelulares, específicamente donde se forman los complejos de unión (Vorbrodt et al., 1994).

La interacción del Ca con metales pesados puede ser un importante elemento del mecanismo fisiopatológico (Shamoo, 1987; Bressler \& Goldstein, 1991). El Cd bloquea 
el Ca en la membrana plasmática (Swandulla \& Armstron, 1989; Ohta et al., 2002) e inhibe la ATPasa-Ca2+ (Visser et al., 1993) aumentando la concentración intracelular de Ca. La substitución de los iones Ca por Cd inhibiría la secreción salival, causando disturbios intracelulares en las glándulas (Abdollahi et al., 2000).

Según Chiarenza et al.(1989), los cambios estructurales y funcionales que ocurren en las glándulas salivales insi- núan una acción desintoxicante, ya que esas glándulas están asociadas al transporte de agua e iones, como los túbulos renales, pudiendo considerarse órganos excretores alternativos para algunos metales. Estos hechos justificarían los resultados observados. Los resultados de este trabajo sugieren que el Cd, durante la lactancia, actúa directamente sobre las glándulas salivales provocando alteraciones significativas. La cría tratada presenta reducción de la ganancia de peso, así como aspectos de inmadurez y menor diferenciación.

FRIEDRICHI, C.; LOPES, R. A.; SALA, M. A.; FELIPPINI, A. L.; ISSA, J. P. M.; WATANABE, I. \& LOPES, T. R. V. P. Effects of cadmium on the rat salivary glands, during lactation. Int. J. Morphol., 27(4):1129-1137, 2009.

SUMMARY: Cadmium (Cd) in air, drinking water and food has the potential to affect the health of people, mainly those who live in highly industrialized regions. Cd affects placental function, can cross the placental barrier and directly modify fetal development. Once the organism is particularly susceptible to the exposition to the Cd during the perinatal period, and that this metal can be excreted in the milk, the aim of the present work was to study the effects of the constant exposition to drinkable water containing low levels of Cd during the lactation, on the salivary glands of the rat. Female rats received ad libitum drinking water containing $300 \mathrm{mg} / \mathrm{l}$ of $\mathrm{CdCl} 2$ throughout the whole lactation. Control animals received a similar volume of water without Cd. Lactant rats ( 21 day old) were killed by lethal dose of anesthetic. The salivary glands were separated, fixed in "alfac" solution for $24 \mathrm{~h}$, and serially sectioned. The $6 \mu \mathrm{m}$ thick sections were stained with hematoxylin and eosin. Nuclear glandular parameters were estimated, as well as cytoplasm and cell volume, nucleus/ cytoplasm ratio, number and surface density, diameters and cell thickness. Mean body weight was $34.86 \mathrm{~g}$ for the control group and 18.56 $\mathrm{g}$ for the Cd-treated group. Histologically, the glandular acini were significantly smaller, the gland ducts were similar in both groups studied. The connective tissue was more abundant. In conclusion, the salivary glands (submandibular, parotid and sublingual) showed retarded growth after Cd intoxication.

KEY WORDS: Cadmium; Rat; Lactation; Salivary Glands; Histometry.

\section{REFERENCIAS BIBLIOGRÁFICAS}

Abdollahi, M.; Dehpour, A. \& Kazemian, P. Alteration by cadmium of rat submandibular gland secretory function and the role of the 1-arginine/nitric oxide pathway. Pharmacol. Res., 42:591-7, 2000.

Antonio, M. T.; Corredor, L. \& Leret, M. L. Study of the activity of several brain enzymes like markers of the neurotoxicity induced by perinatal exposure to lead and/ or cadmium. Toxicol. Lett., 143: 331-40, 2003.

Antonio, M. T.; López, N. \& Leret, M. L. Pb and Cd poisoning during development alters cerebellar and striatal function in rats. Toxicology, 176: 59-66, 2002.

Bhattacharyya, M. H. Bioavailability of orally administered cadmium and lead to the mother, fetus, and neonate during pregnancy and lactation: an overview. Sci. Total Environ., 28: 327-42, 1983.

Bhattacharyya, M. H.; Whelton, B. D. \& Peterson, D. P. Gastrointestinal absorption of cadmium in mice during gestation and lactation: II. Continuous exposure studies.
Toxicol. Appl. Pharmacol., 66:368-75, 1982.

Braga, A. S.; Catirse, A. B. C. E. B.; Lopes, R. A.; Semprini, M. \& Sala, M. A. Efeito tóxico del ión cadmio sobre la glándula submandibular de la rata adulta. Rev. Chil. Anat., 19:183-90, 2001.

Brako, E. E.; Wilson, A. K.; Jonah, M. M.; Blum, C. A.; Cerny, E. A.; Willians, K. L \& Bhattacharyya, M. H. Cadmium pathways during gestation and lactation in control versus metallothionein 1,2-knockout mice. Toxicol. Sci., 71:154-63, 2003.

Bressler, J. P. \& Goldstein, G. W. Mechanism of lead neurotoxicity. Biochem. Pharmacol., 41:479-84, 1991.

Chalkley, H. W. A method for the quantitative morphologic analysis of tissues. J. Nat. Cancer Inst., 4:47-53, 1943.

Chaudhry, I. M.; Kumar, R.; Waterhouse, J. P. \& Chambers, D. A. A kinetic study of rat salivary gland alkaline phosphatase and its inhibition by cadmium. Arch. Oral Biol., 28:741-4, 1983. 
FRIEDRICHI, C.; LOPES, R. A.; SALA, M. A.; FELIPPINI, A. L.; ISSA, J. P. M.; WATANABE, I. \& LOPES, T. R. V. P. Efectos del cadmio sobre las glándulas salivales de rata, durante la lactancia. Int. J. Morphol., 27(4):1129-1137, 2009.

Chiarenza, A.; Elverdin, J. C.; Espinal, E. \& Ciclio, M. J. Effects of cadmium on the function and structure of the rat salivary glands. Arch. Oral Biol., 34:999-1002, 1989.

Christoffersen, J.; Christoffersen, M. R.; Larsen, R.; Rostrup, E.; Tingsgaard, P.; Andersen, O. \& Grandjean, P. Interaction of cadmium ions with calcium hydroxyapatite crystals: a possible mechanism contributing to the pathogenesis of cadmium-induced bone diseases. Calcif. Tissue Int., 42: 331-9, 1988.

Crowe, A. \& Morgan, E. H. Effect of dietary cadmium on iron metabolism in growing rats. Toxicol. Appl. Pharmacol., 145:136-46, 1997.

Elsenhans, B.; Kolb, K.; Schümann, K. \& Forth, W. The longitudinal distribution of cadmium, zinc, copper, iron and metallothionein in the small intestinal mucosa of rats after administration of cadmium chloride. Biol. Trace Elem. Res., 41:31-46, 1994.

Fassett, D. W. Cadmium: Biological effects and occurrence in the environment. Ann. Rev. Pharmacol., 15:425-35, 1975.

Grawé, K. P. \& Oskarsson, A. Cadmium in milk and mammary gland in rats and mice. Arch. Toxicol., 73:519$27,2000$.

Kello, D. \& Kostial, K. Influence of age and milk diet on cadmium absorption from the gut. Toxicol. Appl. Pharmacol., 40:277-82, 1977.

Kelman, B. J.; Walter, B. K.; Jarboe, G. E. \& Sasser, L. B. Effect of dietary cadmium on calcium metabolism in the rat during late gestation. Proc. Soc. Exp. Biol. Med., 158: 614-7, 1978.

Kostial, K.; Kello, D.; Jugo, S.; Rabar, I. \& Maljkovic', T. Influence of age on metal metabolism and toxicity. Environm. Health Perspect., 25:281-5, 1978.

Kostial, K.; Simonovic, I.; Rabar, I. \& Landeka, M. Effect of rat's diet on $85_{\mathrm{Sr}},{ }^{115} \mathrm{mCd}$, and ${ }^{203} \mathrm{Hg}$ absorption in suckling rats. Environm. Res., 25(2):281-5, 1981.

Kozowska, K.; Brzozowska, A.; Sulkowaska, J. \& Roszkowski, W. The effect of cadmium on iron metabolism in rats. Nutr. Res., 39:86-95, 1993.

Lijnen, P.; Staessen, J.; Fagard, R. \& Amery, A. Effect of cadmium on transmembrane $\mathrm{Na}+$ and $\mathrm{K}+$ transport system in human erythrocytes. Brit. J. Ind. Med., 48: 392-8, 1991.
Ludovice, J.; Afonso, R. L.; Lopes, R. A.; Sala, M. A.; Mattos, M. G. C. \& Watanabe, I. Alterações presentes na glândula submandibular do rato, determinadas pelo cádmio durante a lactação. Simp. Inic. Cient. USP, 7:217, 1999.

Loeser, E. \& Lorke, D. Semichronic oral toxicity of cadmium. I. Studies on rats. Toxicology, 7:215-24, 1977.

Lucis, O. J.; Lucis, R. \& Shaikh, Z. A. Cadmium and zinc in pregnancy and lactation. Arch. Environ. Health, 25:1422, 1972.

Morselt, A. F. Environmental pollutants and diseases. A cell biological approach using chronic cadmium exposure in the animal model as a paradigm case. Toxicology, 70:1132, 1991.

Nogawa, K. Itai-itai disease and follow-up studies. In: Cadmium in Environment (Nriagu, J.O., Ed.). New York, John Wiley \& Sons, 1981.

Nordberg, G. F. Effects of long-term cadmium exposure on the seminal vesicles of mice. J. Reprod. Fertil., 45:165$7,1975$.

Ohta, H.; Ichikawa, M. \& Seki, Y. Effects of cadmium intake on bone metabolism of mothers during pregnancy and lactation. Tohoku J. Exp. Med., 196:33-42, 2002.

Paula Lopes, T. R.V.; Semprini, M.; Lopes, R. A.; Sala, M.A.; Mattos, M. G. C. \& Watanabe, I. Morphometric study of the effects of cadmium on the structure of the rat submandibular gland. Investigação, 1:58-61, 1999.

Pinkerton, C.; Hammer, D. I.: Bridbord, K.; Creason, J. P. \& Kent, J. L. Human milk as dietary source of cadmium and lead. In: Trace substances in environmental health, 4. Missouri, FSTA, 1976.

Pinto, D. M. G.; Lopes, R. A.; Costa, J. R. V.; Lacerda, S.A.; Semprini, M.; Sala, M. A. \& Watanabe, I. Ação do cádmio na glândula submandibular de fetos de ratas. Estudo estereológico. Rev. Esc. Farm. Odont. Alfenas, 20:13-5, 1998.

Plocke, D. J.; Levinthal, C. \& Vallee, B. L. Alkaline phosphatase of Escherichia coli: a zinc metalloenzyme. Biochemistry, 1:373-8, 1962.

Prozialeck, W. C. \& Lamar, P. C. Effects of glutathione depletion on the cytotoxic actions of cadmium in LLCPK 1 cells. Toxicol. Appl. Pharmacol., 134:285-95, 1995. 
Sala, M. A.; Komesu, M. C.; Lopes, R. A. \& Maia Campos, G. Karyometric study of basal cell carcinoma. Braz. Dental J., 5:11-4, 1994.

Sala, M. A.; Matheus, M. \& Valeri, V. Estimation of the average diameter of human placental villi by a stereological method. Microsc. Acta, 82:339-42, 1980.

Sala, M. A.; Matheus, M. \& Valeri, V. A new stereological method for estimating the thickness of a tissular layer on random sections. Mikroskopie, 38:127-30, 1981.

Sasser, L. B. \& Jarboe, G. E. Intestinal absorption and retention of cadmium in neonatal rat. Toxicol. Appl. Pharmacol., 41:423-31, 1977.

Sasser, L. B. \& Jarboe, G. E. Intestinal absorption and retention of cadmium in neonatal pigs compared to rats and guinea pigs. J. Nutr., 110:1641-7, 1980.

Sasser, L. B.; Jarboe, G. E.; Walter, B. K. \& Kelman, B. J. Absorption of mercury from ligated segments of the rat gastrointestinal tract. Proc. Soc. Exp. Biol. Med., 157: 57-60, 1978.

Schäfer, S. G. \& Elsenhans, B. Iron retention and distribution in the cadmium-induced iron deficiency. Ecotoxicol. Environ. Saf., 10:128-41, 1985.

Schulte-Löbbert, F. J.; Bohn, G. \& Arker, L. Untersuchungen zur exogenen Cadmiumaufnahme bei Säuglingen und Kleinkindern. Beitr. Gericht. Med., 36:491-5, 1978.

Schümann, K.; Friebel, P. Schmolke, G. \& Elsenhans, B. State of iron and cadmium tissue accumulation as a function of growth in young rats after oral cadmium exposure. Arch. Environ. Contam. Toxicol., 31:483-7, 1996.

Shamoo, A. E. Biological targer sites of mercurials. In: The Toxicity of Methyl Mercury (Eccles, C.U. \& Annau, Z., Eds.). Baltimore: Johns Hopkins University Press, 1987.

Shoham, M.; Kalb, A. J. \& Pecht, I. Specificity of metal ion interaction with concanavalin A. Biochemistry, 12:19147, 1973.

Sprent, P. \& Smeeton, N. C. Applied nonparametric statistical methods. $3^{\text {rd }}$ ed. Boca Raton: Chapman \& Hall/ CRC, 2001.

Sternowsky, H. J. \& Wessolowski, R. Lead and cadmium in breast milk - higher levels in urban vs rural mothers during the first 3 month of lactation. Arch. Toxicol., 57:415,1985 .
Swandula, D. \& Armstrong, C. M. Calcium channel block by cadmium in chicken sensory neurons. Proc. Natl. Acad. Sci., 86:1736-40, 1989.

Tomkeieff, S. I. Linear intercepts, area and volume. Nature, 155:24, 1945

Visser, G. J.; Peters, P. H. \& Theuvenet, A. P. Cadmium ion is a non-competitive inhibitor of red cell $\mathrm{Ca} 2+-$ ATPase activity. Biochem. Biophys. Acta, 1152:26-34, 1993.

Vorbrodt, A. W.; Trowbridge, R. S. \& Dobrogowaska, D. H. Cytochemical study of the effect of aluminium on cultured brain microvascular endothelial cells. Histochem. J., 26:119-26, 1994.

Webster, W. S. Cadmium-induced fetal growth retardation in the mouse. Arch. Environ, Health, 33:36-42, 1978.

Webster, W. S. \& Valois, A. A. The toxic effects of cadmium on the neonatal mouse CNS. J. Neuropathol. Exp. Neurol., 40:247-57, 1981.

Whelton, B. D.; Bhattacharyya, M. H.; Carnes, B. A.; Moretti, E. S. \& Peterson, D. P. Female reproduction and pup survival and growth for mice fed a cadmium-containing purified diet through six consecutive rounds of gestation and lactation. J. Toxicol. Environ. Health, 24:321-43, 1988.

WHO. Technical report series 505. Evaluation of certain food additives and the contaminants mercury, lead and cadmium. 16 $6^{\text {th }}$ Report of the Joint FAO/WHO Expert Committee on Food Additives. Geneva: WHO, 1972.

Dirección para correspondencia:

Prof. Dr. Ruberval Armando Lopes

Faculdade de Odontologia de Ribeirão Preto

Universidade de São Paulo

Avenida do Café s/n

CEP 14040-904

Ribeirão Preto - SP

BRASIL

e-mail: ruberlopes@yahoo.com.br

Recibido : 19-06-2009

Aceptado: 23-09-2009 
